\title{
PERFIL SOCIOECONÔMICO DOS PESCADORES ARTESANAIS DE DOIS LAGOS PERIURBANOS DE SANTARÉM, ESTADO DO PARÁ
}

Socioeconomic profile of the artisanal fishermers in two peri-urban lakes of Santarém, state of Pará

Perfil socioeconómico de los pescadores artesanales en dos lagos periurbanos de Santarém, estado de Pará

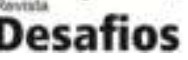

Artigo Original Original Article Artículo Original

\author{
Yohanna Gabriely Sousa Rabelo ${ }^{1}$, Elizabete de Matos Vaz ${ }^{2}$, Diego Maia Zacardi ${ }^{3 *}$ \\ ${ }^{1}$ Curso de Engenharia de Pesca, Universidade Federal do Oeste do Pará, Santarém, Pará, Brasil. \\ ${ }^{2}$ Pós-Graduação em Mestrado em Recursos Aquáticos Continentais Amazônicos, Universidade Federal do Oeste \\ do Pará, Santarém, Pará, Brasil. \\ ${ }^{3}$ Docente e Orientador do Programa de Pós-Graduação em Recursos Aquáticos Continentais Amazônicos \\ (PPGRACAM), em Santarém, Pará, Brasil.
}

*Correspondência: Universidade Federal do Oeste do Pará, Universidade Federal do Oeste do Pará. Avenida Marechal Rondon, 2946, sala 225, Laboratório de Ecologia do Ictioplâncton - Aparecida 68040070 - Santarém, PA - Brasil.e-mail: dmzacardi@hotmail.com

\section{RESUMO}

O artigo teve como objetivo caracterizar a pesca e o perfil socioeconômico dos pescadores atuantes em dois lagos periurbanos de Santarém (PA), por meio da aplicação de 68 formulários semiestruturados. A maioria dos entrevistados eram do sexo masculino (69\%), com idade entre 19 e 80 anos, baixos níveis de escolaridade e renda. Os resultados técnico-operacionais revelam a atividade como artesanal e de pequena escala, praticada por canoas motorizadas, sendo executada por pescadores de dedicação parcial ou exclusiva e com produção destinada em partes à subsistência e ao comércio, utilizando importante meio de subsistência para os pescadores locais. Como pontos negativos foram relatados a falta de fiscalização, a pesca multiplicidade de apetrechos com destaque para o uso da malhadeira e da captura de pacus, aracus, bocó (juvenil de tambaqui), jaraquis e tucunarés. Em toda extensão dos lagos ocorre a prática da pesca artesanal indicando a relevância destes mananciais como predatória e o mau uso e degradação dos recursos naturais. Os pescadores necessitam da atuação do poder público na promoção de ações socioambientais nestes mananciais para a manutenção da atividade e preservação dos recursos pesqueiros, geração de emprego, renda e melhoria da qualidade de vida da população que depende da pesca.

Palavras-chave: Pesca artesanal; Ambiente lacustre; Sustentabilidade

\section{ABSTRACT}

The objective of this article was to characterize the fishing and the socioeconomic profile of active fishermen in two peri-urban lakes of Santarém (PA), through the application of 68 semi-structured forms. The majority of interviewed people was male (69\%), aged with ages between 19 to 80 years, low levels of education and income. The technical-operational results reveal the activity as artisanal and small-scale, practiced by motorized canoes, done by fishers with partial or exclusive dedication. The production is destined in part for the subsistence, in part for the trade. It was observed the use of a large number of tools, highlighting for the use of fishing net and the caught of pacus, aracus, bocó (youth of tambaqui), jaraquis and tucunarés. Throughout the lakes occurs the artisanal fishing, which is indicating the relevance of these water sources as an important livelihood to the local fishers. Fishermen need the government's role in promoting social and environmental actions in these watersheds to maintain activity and preservation of fisheries resources, generation of employment, income and improving people's quality of life depends on fishing.

Keywords: Artisanal fishing; Lacustrine environment; Sustainability 


\section{RESUMEN}

El objetivo del articulo fue caracterizar la pesca y el perfil socioeconómico de los pescadores activos en dos lagos peri-urbanas de Santarém (PA), por médio de la aplicación de 6868 formularios semiestructurados. La mayoría de los entrevistados eran del sexo masculino (69\%), con edad entre 19 y 80 años, bajos niveles de escolaridad y renta.

Los resultados técnico-operativos, revelan la actividad como artesanal y de pequeña escala, practicada por canoas motorizadas, siendo ejecutada por pescadores de dedicación parcial o exclusiva y con producción destinada en partes a la subsistencia y al comercio, utilizando multi-petrechos, con destaque para el uso de la mallera y de la captura de pacus, aracus, bocó (juvenil de tambaqui), jaraquis y tucunarés. En toda extensión de los lagos ocurre la práctica de la pesca artesanal indicando la relevancia de estos manantiales como importante medio de subsistencia para los pescadores locales. Como puntos negativos se han reportado la falta de fiscalización, la pesca predatoria y el mal uso y degradación de los recursos naturales. Los pescadores necesitan el papel del gobierno en la promoción de acciones sociales y ambientales en estas cuencas para mantener la actividad y la conservación de los recursos pesqueros, la generación de empleo, renta y mejorar la calidad de vida de las personas depende de la pesca.

Descriptores: Pesca artesanal; Ambiente lacustre; Sostenibilidad

\section{INTRODUÇÃO}

A pesca artesanal é realizada, a nível mundial, por aproximadamente $90 \%$ do total de pescadores, representando um contingente de aproximadamente 40 milhões de pessoas empregadas diretamente neste setor (Batista et al., 2011; FAO, 2012; Coe, 2016) e a situação não é diferente no Brasil onde esta modalidade de pesca, em 2013, englobava cerca de 90,3\% ou 440.266 trabalhadores (Campos e Chaves, 2016).

Segundo os dados do Registro Geral de Atividade Pesqueira (RGP) do Ministério da Pesca e Aquicultura, em 2010, o estado do Pará apresentava 223.501 registros de pescadores, totalizando o estado com maior número de trabalhadores nesse ramo de atividade, aproximadamente $26,17 \%$ do total de registros nacionais (BRASIL, 2012).

A pesca artesanal é uma das atividades econômicas mais tradicionais praticada nas áreas de várzea no Baixo Amazonas (Pará) associada à obtenção de alimentos, à população local, ocupação de mão-de-obra e à geração de renda, obtida por meio da comercialização do pescado nos mercados e feiras locais (Vaz, 2016; Zacardi et al., 2017) e da exportação para outras regiões do país ou mesmo para o exterior, oportunizando desenvolvimento social e econômico.

Contudo, as informações existentes sobre a pesca da região são insuficientes, devido à falta de dados sistemáticos e contínuos para quantificar e caracterizar essa atividade, além da carência generalizada de informações sobre os aspectos socioeconômico dos pescadores, tecnologia empregada e estrutura de organização que são pouco explorados e negligenciados nos estudos pesqueiros (Walter, 2000; Alves da Silva et al., 2009). Mas apresentam extrema importância para implementação de medidas de manejo dos estoques, assim como para o acréscimo econômico destas populações.

Dessa forma, este artigo apresenta resultados da caracterização socioeconômica dos pescadores artesanais e da atividade pesqueira exercida em dois lagos periurbanos de Santarém, Pará, com a finalidade de compreender sua forma de vida e de reunir subsídios críticos para ajustes nas ações de gerenciamento das políticas públicas do setor pesqueiro da região.

\section{MATERIAIS E MÉTODOS}


O município de Santarém, no estado do Pará, ocupa a área de $24.154 \mathrm{~km}^{2}$, localizando-se entre os paralelos $2^{\circ} \mathrm{S}$ e $4^{\circ} \mathrm{S}$ e os meridianos $56^{\circ} \mathrm{W}$ e $54^{\circ} \mathrm{W}$. O lago Maicá está localizado na porção oeste do município, na junção dos rios Amazonas e Tapajós, e o lago do Juá situa-se a cerca de $9 \mathrm{Km}$ a oeste do centro da cidade de Santarém, à montante do rio tapajós, em relação à cidade (Figura 1). Diversos pescadores e moradores fazem uso dos lagos para desenvolver a prática de pesca.

Figura 1. Localização da área de estudo, lagos Juá e Maicá, no entorno da cidade de Santarém, Pará.

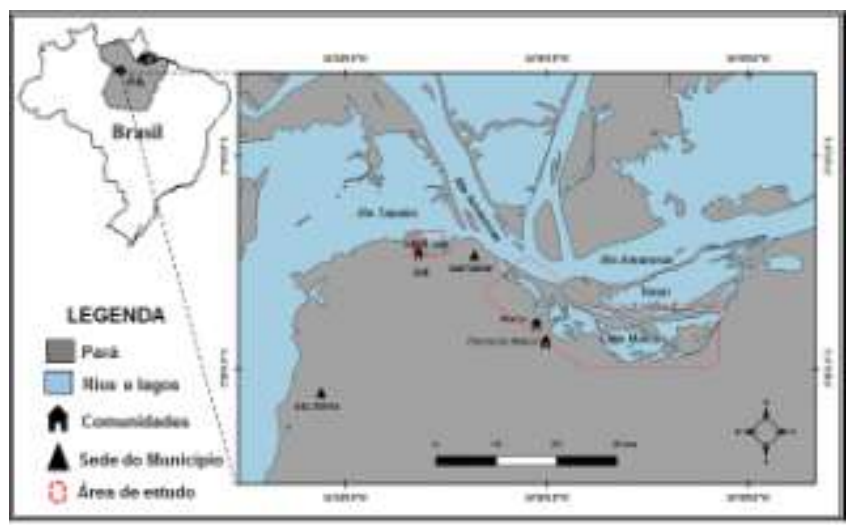

Esses ecossistemas lacustres sofrem influências por águas de várias cabeceiras, igarapés, bem como pela periodicidade regular do ciclo hidrológico do rio Amazonas/Tapajós e das chuvas locais. As regiões que margeiam os lagos apresentam uma extensa planície inundável, domínio de floresta aberta, áreas de tensão ecológica, formações aluviais e áreas antrópicas.

O clima local corresponde a tropical úmido do tipo Am, com a temperatura média anual de $27.7^{\circ} \mathrm{C}$ e pouca variabilidade na umidade e temperatura do ar (Köppen e Geiger, 1928). A precipitação média é de $2.096 \mathrm{~mm}$, com as maiores concentrações entre os meses de dezembro a junho, sendo março o mês de maior precipitação (Costa et al., 2013).
A coleta de dados foi realizada de forma fragmentada e aleatória por meio da aplicação de 68 formulários semiestruturados (perfazendo mais de $30 \%$ do total de pescadores cadastrados junto a Colônia de Pescadores e Pescadoras Z-20), com 70 perguntas objetivas e subjetivas, mediante adesão voluntária, durante o período de maio de 2015 a março de 2016, visando obter informações sobre os aspectos sociais e econômicos dos pescadores, formas de exploração dos recursos pesqueiros, tecnologia empregada na atividade, conservação, comercialização do pescado, entre outros, por meio de abordagem direta aos pescadores e demais atores sociais envolvidos com a prática da pesca (Figura 2), registrando a realidade do sistema pesqueiro desse segmento social, que faz parte de uma atividade econômica que é fonte básica de renda para muitas famílias ribeirinhas do município.

A técnica de entrevista tem sido utilizada em diversos estudos de extensão pesqueira seja para caracterizar o ofício da pesca desenvolvido por uma comunidade (Zacardi et al., 2014; Zacardi et al., 2017), compreender o etnoconhecimento ecológico local e interação da biota do meio com a atividade pesqueira (Braga e Rebêlo, 2014; 2015) ou a percepção sobre as questões ambientais de uma região (Brito et al., 2015).

Figura 2. Entrevista e aplicação de formulários aos pescadores atuantes nos lagos periurbanos de Santarém, Pará.

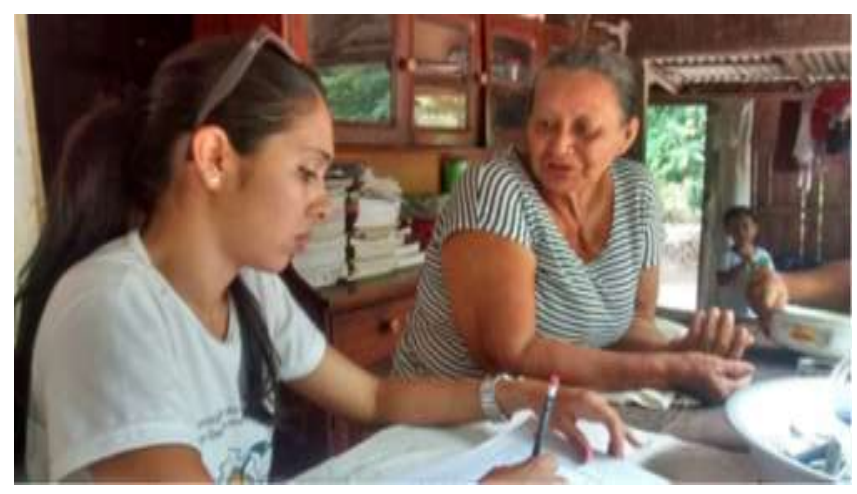


Paralelamente à aplicação dos formulários foram efetuados registros fotográficos, com o objetivo de ilustrar as informações obtidas, como também vivenciar a rotina com participação nas atividades de interesse dos pesquisadores. Além de conversas formais, informais, observações in loco e $\mathrm{o}$ acompanhamento de reuniões nas comunidades do entorno dos lagos.

No Laboratório de Ensino Multidisciplinar em Recursos Pesqueiros da Universidade Federal do Oeste do Pará, foram realizadas as atividades de tratamento das informações coletadas. De acordo com as visitas empreendidas nas comunidades, foi possível estabelecer perante aos líderes um elo de confiança, obtida assim uma autorização da pesquisa junto a Associação de Moradores e nos Núcleos de Base da Colônia de Pescadores Z-20.

As informações das variáveis socioeconômicas e operacionais da atividade pesqueira foram organizadas, tabuladas, sistematizadas e submetidas à estatística descritiva para cálculo de frequência, medidas de tendência central e medida de dispersão dos dados, como descrito por Triola (2005) e Fonseca e Martins (2008).

\section{RESULTADOS E DISCUSSÃO}

Aspectos socioeconômicos dos pescadores

As pescarias exercidas nos lagos Juá e Maicá tem caráter artesanal e de pequena escala, são diversificadas e caracterizadas por uma complexa base de informações influenciada por costumes tradicionais e são desenvolvidas por diferentes gerações, em que as relações de trabalho, social e de produção se caracterizam pela participação de mão de obra familiar ou de grupos de vizinhança, constituindo um importante meio de subsistência para as comunidades que se desenvolve no entorno dos lagos. As informações cedidas pelos pescadores indicam que os mesmos utilizam os lagos e suas áreas adjacentes para o trabalho (pesca) e lazer.

Existem duas características marcantes nos pescadores artesanais em atividade nos lagos estudados. A primeira é a idade média relativamente alta, de 49 anos, variando entre 19 e 80 anos $( \pm 13)$. A segunda refere-se ao baixo nível de escolaridade, pois a maioria declarou possuir apenas o ensino fundamental incompleto (53\%), com média de 4 anos de estudo, valor que está abaixo da média nacional que é de 5,7 anos (Petrere Júnior, 2004; Aguiar et al., 2010).

A baixa escolaridade acaba por comprometer as ações de capacitação e de conscientização organizativa da classe, condição indispensável para promoção do setor, culminando na fraca atuação política dos pescadores (Zacardi et al., 2014).

Santos (2005) justifica essa situação pela dificuldade da maioria dos pescadores ao acesso à escola em comunidades do nordeste paraense, no período da infância e adolescência, dificultando o ingresso e a permanência na instituição de ensino. Contudo, ressalta-se que, na área urbana, no entorno dos lagos estudados, existem escolas da rede pública estadual de ensino fundamental e médio.

Os resultados das entrevistas mostraram que a maioria dos pescadores eram do sexo masculino $(69 \%)$. Este percentual pode ter sido mascarado em relação à participação das mulheres, em virtude de que os seus respectivos cônjuges também eram pescadores e foram os responsáveis pela maioria das informações, realidade já comentada por diversos trabalhos na região Amazônica (Sá-Oliveira et al., 2013; Zacardi et al., 2014, Zacardi, 2015; Zacardi et al., 2017). 
Dentre os estrevistados, $47 \%$ se declaravam casados, $27 \%$ com união estável, $18 \%$ solteiros, $6 \%$ separados e apenas $2 \%$ viuvos, nascidos no município de Santarém (82\%), obtendo renda mensal menor ou igual a 1 salário mínimo (72\%) e tempo médio de 35 $( \pm 15)$ anos de atuação na atividade pesqueira. Estes dados e outros relacionados ao aspecto socioeconômico estão especificados na tabela 1 .

A realidade socioeconômica dos pescadores atuantes nesses lagos é similar à de outras comunidades ribeirinhas estudadas na Amazônia, principalmente no que diz respeito a idade, renda, escolaridade e tempo de pesca (Carvalho-Júnior et al., 2009; Borcem et al., 2011; Santos-Filho et al., 2011;
Zacardi et al., 2014, Zacardi et al., 2017) e em outras partes do Brasil (Seixas e Begossi, 2000).

Grande parte dos pescadores mencionaram não conseguir sustentar sua família com o rendimento oriundo apenas da pesca, esse fato também foi observado em outros municípios do estado do Pará, onde pescadores sobrevivem com renda inferior a um salário mínimo (Lourenço et al., 2003; Santos, 2005; Borcem et al., 2011). Esta realidade direciona muitos integrantes a alternar ou migrar de setor, abandonando a atuação e passando a operar em outras atividades econômicas (Zacardi et al., 2014), colaborando no distanciamento dos jovens da atividade pesqueira.

Tabela 1. Aspectos socioeconômicos dos pescadores entrevistados e atuantes nos lagos Juá e Maicá, Santarém, Pará.

\begin{tabular}{|c|c|c|}
\hline \multicolumn{2}{|c|}{ Informações (total de entrevistados $=68$ ) } & Participação relativa $(\%)$ \\
\hline \multirow{6}{*}{ Faixa etária } & $19-28$ & $7 \%$ \\
\hline & $29-38$ & $15 \%$ \\
\hline & $39-48$ & $15 \%$ \\
\hline & $49-58$ & $32 \%$ \\
\hline & $59-68$ & $25 \%$ \\
\hline & $>68$ & $6 \%$ \\
\hline \multirow{2}{*}{ Sexo } & Masculino & $69 \%$ \\
\hline & Feminino & $31 \%$ \\
\hline \multirow{4}{*}{ Escolaridade } & Sem instrução escolar & $13 \%$ \\
\hline & Ensino fundamental incompleto & $53 \%$ \\
\hline & Ensino fundamental completo & $26 \%$ \\
\hline & Ensino médio completo & $7 \%$ \\
\hline \multirow{3}{*}{$\begin{array}{l}\text { Origem dos } \\
\text { pescadores }\end{array}$} & Santarém & $82 \%$ \\
\hline & Outros municípios do estado & $15 \%$ \\
\hline & Outro estado & $3 \%$ \\
\hline \multirow{3}{*}{ Renda mensal } & Subsistência & $7 \%$ \\
\hline & $<1$ salário mínimo & $72 \%$ \\
\hline & 1 a 3 salários mínimos & $21 \%$ \\
\hline \multirow{4}{*}{$\begin{array}{l}\text { Número de } \\
\text { dependentes }\end{array}$} & Nenhuma & $7 \%$ \\
\hline & $<2$ pessoas & $2 \%$ \\
\hline & 2 a 5 pessoas & $59 \%$ \\
\hline & $>5$ pessoas & $31 \%$ \\
\hline \multirow{2}{*}{ Moradia } & Própria & $96 \%$ \\
\hline & Alugada & $4 \%$ \\
\hline \multirow{2}{*}{$\begin{array}{l}\text { Energia } \\
\text { elétrica }\end{array}$} & Sim & $91 \%$ \\
\hline & Não & $9 \%$ \\
\hline \multirow{3}{*}{$\begin{array}{c}\text { Abastecimento } \\
\text { de Água }\end{array}$} & Microssistema & $38 \%$ \\
\hline & Cacimba & $29 \%$ \\
\hline & Poço artesiano & $32 \%$ \\
\hline Outras & Prestação de serviços diversos & $35 \%$ \\
\hline atividades & Agricultura & $12 \%$ \\
\hline
\end{tabular}




\begin{tabular}{ccc}
\hline & Carpintaria & $9 \%$ \\
& Ajudante de pedreiro & $6 \%$ \\
& Comerciantes & $18 \%$ \\
& Atividades assalariadas & $21 \%$ \\
\hline \multirow{2}{*}{ Frequência da } & Diária & $41 \%$ \\
Pesca & Semanal & $50 \%$ \\
& Mensal & $9 \%$ \\
\hline \multirow{2}{*}{ Tempo de } & $0-15$ & $10 \%$ \\
pesca/ano & $15-30$ & $29 \%$ \\
& $30-45$ & $35 \%$ \\
& $45-60$ & $22 \%$ \\
\hline
\end{tabular}

Mesmo com o tempo de atividade pesqueira sendo superior a três décadas, notou-se que ainda nem todos os pescadores possuem registro $(75 \%)$. Para metade dos entrevistados a pesca é a única atividade econômica, o restante afirmou desenvolver outras atividades (prestação de serviços diversos "bico", agricultura, carpintaria, ajudante de pedreiro, comerciantes, atividades assalariadas - carteira assinada), principalmente durante a entressafra (período que se caracteriza pela menor produção pesqueira na região - março a junho - em consequência da elevação do nível do rio, fato que proporciona a queda da produção devido a dispersão dos peixes nas florestas alagadas, dificultando a captura), o que não impede a atuação desses serviços conforme a necessidade financeira. Essas atividades adicionais à pesca são importantes, pois contribuem para a geração de renda complementar para as famílias.

Algumas poucas famílias de pescadores estão submetidas a condições de pobreza e vulnerabilidade socioeconômica, visto que não obtêm acesso a diversos bens duráveis (geladeira, televisão...) e serviços públicos como água, saneamento básico, saúde, energia entre outros. Tal fato decorre das dificuldades de acesso à renda por essa categoria de produtor, em consequência dos baixos rendimentos mensais inferiores a um salário mínimo. Contudo, a maioria reside em habitações com fornecimento de eletricidade e água fornecida pela Companhia de Saneamento do Pará (Cosanpa).

A qualidade de vida dos pescadores também pode ser aferida através das características de suas residências, observa-se que as moradias são predominantemente mistas com paredes de alvenaria e de madeira, cobertas com telha de barro e/ou fibrocimento, com pisos de barro ou cimento rústico.

\section{Caracterização da atividade de pesca}

Os resultados técnicos e operacionais revelam uma atividade pesqueira praticada por vários tipos de embarcações de madeira que possuem pouca autonomia, com a predominância de canoas motorizada (5,5 e 6,5 HP), conhecidas como rabetas, movidas à gasolina (com capacidade de até $400 \mathrm{~kg}$ ), podem variar de 2,5 a 14 metros de comprimento, sendo a maioria delas não cadastradas. O proprietário da embarcação é, normalmente, um dos pescadores que participa de toda a operação de pesca, e o pescado, geralmente, é comercializado vivo (inteiro) e/ou por cambada (composta por quatro a dez peixes de pequeno porte agrupados e amarrados a uma fibra vegetal ou corda que passa pela abertura opercular ver figura 3), de forma direta, normalmente distribuído para moradores e visitantes. 
Figura 3. Comercialização do pescado em forma de cambada, no entorno do lagos periurbanos de Santarém, Pará.

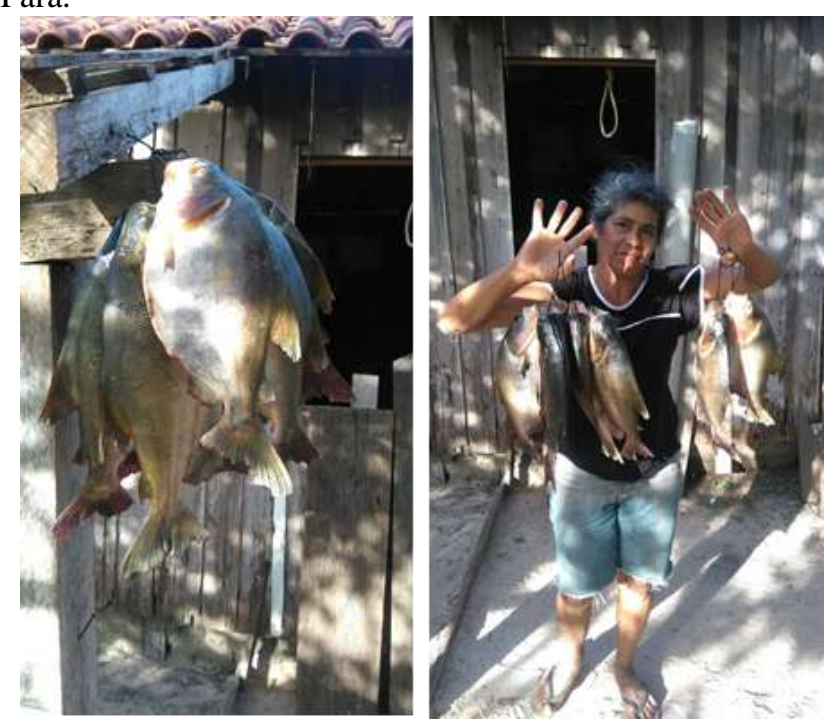

Os pescadores não se limitam apenas aos

lagos Juá e Maicá, citam também como áreas de pesca os lagos Grande, Mapiri, Papucu e o rio Amazonas. Dentre as artes de pesca utilizadas pelos entrevistados em ordem decrescente de importância, foram a rede de emalhar (malhadeira), caniço, tarrafa, espinhel, linha de mão, arpão, arco e flecha e zagaia, explorando 34 categorias de pescados, com destaque para o uso da malhadeira e da captura de pacus (Myleinae), aracus (Leporinus spp. e Schizodon spp.), bocó (juvenil de tambaqui - Colossoma macropomum), jaraquis (Semaprochilodus spp.) e tucunarés (Cichla), por apresentarem maior disponibilidade no ambiente, valor de mercado e/ou pela preferência dos consumidores.

No entanto, a prática mais comum envolve a utilização de mais de um apetrecho, os quais são selecionados em decorrência da área, profundidade, período do dia ou espécie alvo. A rede de emalhar destaca-se por ser o apetrecho mais utilizado, geralmente possuem altura e comprimento variável, dispostas verticalmente na coluna d'água por uma série de flutuadores (boias de isopor) na parte superior, e chumbo ou cabo chumbado na parte inferior. Algumas características da espessura do nylon e o tamanho da malha podem variar de acordo com as espécies capturadas, são colocadas durante o dia, ficando submersa entre 8 e 12 horas, sendo responsável pela captura de diversas espécies de peixes.

A pesca realizada nos lagos pode ser caracterizada como multi-apetrechos, em razão das capturas ocorrerem com uma variedade de métodos e artes de pesca, as quais se relacionam com o tipo de ambiente explorado e com as espécies-alvo das pescarias, prática comum em áreas de pesca do estado (Cintra et al., 2009; Zacardi et al., 2014; Zacardi, et al., 2017).

A maior parte dos pescadores alegou efetuar o descarte de indivíduos durante a atividade de pesca. O comportamento mais frequente foi o rejeito de peixes considerados "lisos" ou "remosos" como alguns bargres. Entretanto, descartam também as piranhas e peixes pequenos (juvenis), neste caso, independentemente da ordem. De acordo com Vaz (2016) essa estratégia de rejeito e soltura de alguns peixes capturados, que não agradam o paladar ou que não possuem valor de mercado, ou ainda, por se encontrarem em estágios iniciais de desenvolvimento, demonstra certa preocupação por partes dos pescadores, no tocante a seletividade dos apetrechos e com a sustentabilidade dos recursos pesqueiros.

A pesca é executada por pescadores de dedicação parcial ou exclusiva, com uma pequena parcela da produção direcionada apenas para subsistência e grande parte destinada à comercialização. Após a captura, geralmente, o pescado é acondicionado em caixas isotérmicas com gelo para manter o pescado resfriado. Mas, alguns 
pescadores ainda armazenam diretamente sobre a superfície da embarcação.

A importância da pesca local é indiscutível, seja do ponto de vista econômico ou social. No entanto, $94 \%$ dos pescadores entrevistados se mostraram preocupados, pois nos últimos anos tem ocorrido uma redução das espécies de peixes capturáveis e apontaram vários fatores responsáveis, entre eles: o constante aumento da quantidade de pescadores tanto dos membros da comunidade como os de outras localidades, a pesca no período do defeso (período de reprodução dos peixes e de proibição da pesca para a preservação das espécies), a pesca pouco ou nada seletiva, o uso de malhadeiras com malhas pequenas (distância entre nós opostos), a destruição dos habitats naturais pela criação de búfalos e os arrastões (é uma estratégia de pesca que opera com redes de arrasto/cerco em formato de saco que são puxadas até as margens capturando e retendo todo tipo e tamanho de pescado).

Nos conflitos de pesca os principais atores são, de um lado, os ribeirinhos pescadores das comunidades localizadas nos lagos e, de outro, os pescadores itinerantes, denominados "de fora" ou "invasores", provenientes de outros locais e pescam em águas consideradas comunitárias.

Devido a esses conflitos muitas comunidades ribeirinhas vem desenvolvendo seus próprios sistemas de gerenciamento dos recursos pesqueiros. É assim que surgiram os denominados "acordos de pesca" e os sistemas de "reserva de lagos", formas populares de controle dos recursos de livre acesso, baseadas nas experiências de manejo, culturalmente enraizadas nas comunidades tradicionais (Isaac et al., 1993; McGrath et al., 2008).

Nas políticas pesqueiras e de conservação no Brasil, ainda impera o manejo de caráter centralizador imposto por instituições governamentais. E uma alternativa a essa política "de cima para baixo" seria envolver as comunidades locais em estratégias de co-manejo, também designado manejo colaborativo, em que os pescadores são peças-chave no processo de decisão e implementação das estratégias de gestão a serem adotadas (Begossi, 2004).

A aplicação convencional do manejo pesqueiro fundamentado exclusivamente em métodos científicos, e excluindo o conhecimento tradicional dos pescadores, é encarada por Schafer e Reis (2008) como uma alternativa de difícil implementação, inoperante e caro, pois os pescadores não fazem parte do processo de tomada de decisão, e consequentemente, não cumprem as regras estabelecidas, comprometendo as ações de gestão e ordenamento dos recursos naturais em parceria.

\section{CONCLUSÃO}

A atividade pesqueira artesanal praticada nos lagos Juá e Maicá não é apenas uma forma de obtenção de renda, mas um modo de subsistência fundamental para os pescadores e que precisa ser preservado. A pesca é praticada por pequenas embarcações de madeira com pouca autonomia, utilizando multiplicidade de apetrechos de pesca na captura de 34 categorias de pescado, sendo realizada por um grupo social preocupado em gerenciar e cuidar do recurso pesqueiro, contribuindo de forma sustentável.

Dessa forma há necessidade de acompanhar e identificar os atores, denominados de "invasores", que estão influenciando negativamente a atividade de pesca através de práticas ilegais e predatórias, sendo evidente a importância de ações de monitoramento dos recursos pesqueiros nos lagos. E deve-se considerar as informações técnico-científicas, os instrumentos de manejo da pesca e o uso adequado do ambiente que assegure as condições de existência e 
sobrevivência dos peixes, pois a proibição da pesca não garantirá o retorno do peixe, e sim através de uma gestão integrada e participativa que contemple os diferentes interesses de todos os segmentos da sociedade envolvidos.

A estrutura deficiente de captação e comercialização dos produtos advindos da pesca condiciona a frágil perspectiva de desenvolvimento para o setor pesqueiro local. Portanto, ressalta-se a importância da realização de um estudo integrado (recursos pesqueiros, pescadores e ambiente) buscando subsídios ao ordenamento e manejo correto do espaço e dos recursos exploráveis, bem como o respeito pelo conhecimento tradicional permitindo a manutenção da qualidade do meio ambiente, a conservação dos recursos naturais e cognitivos para usufruto tanto das gerações presentes quanto futuras.

\section{AGRADECIMENTOS}

Os autores agradecem aos pescadores dos Lagos Juá e Maicá pelas informações fornecidas para o desenvolvimento desse trabalho e ao Instituto de Ciências e Tecnologia das Águas, da Universidade Federal do Oeste do Pará (UFOPA), pela cessão da infraestrutura para o desenvolvimento do trabalho.

Todos os autores declararam não haver qualquer potencial conflito de interesses referente a este artigo.

\section{REFERÊNCIAS}

ALVES DA SILVA, M.E.P.; CASRO, P.M.G.; MARUYAMA, L.S.; PAIVA, P. Levantamento da pesca e perfil socioeconômico dos pescadores artesanais profissionais no reservatório Billings. Boletim do Instituto de Pesca. v.35, n.4, p.531-543, 2009.

BATISTA, M.I.; BAETA, F.; COSTA, M.J.; CABRAL, H.N. MPA as management tools for small-scale fisheries: the case study of Arrábida Marine Protected Area (Portugal). Ocean Coastal Management. v.54, n.2, p.137-147, 2011.
BEGOSSI, A. Ecologia Humana. In: BEGOSSI, A. (org.) Ecologia de Pescadores da Mata Atlântica e da Amazônia. São Paulo: Fapesp/Hucitec, p. 13-36, 2004.

BORCEM， E.R.; FURTADO-JÚNIOR， I.; ALMEIDA, I.C.; PALHETA, M.K.S.; PINTO, I.A.A atividade pesqueira no município de MarapanimPará, Brasil. Revista de Ciências Agrárias. v.54, n.3, p.189-201, 2011.

BRAGA, T.M.P.; REBÊLO, G.H. Conhecimento tradicional dos pescadores do baixo rio Juruá: aspectos relacionados aos hábitos alimentares dos peixes da região. Interciência. v.39, n.9, p. 659-665, 2014.

BRAGA, T.M.P.; REBÊLO, G.H. Usos da fauna por comunitários da Reserva Extrativista do Baixo Juruá, Amazonas, Brasil. Paper do NAEA. v.4, n.347, p. 125, 2015.

BRASIL. Ministério da Pesca e Aquicultura. Boletim estatístico da pesca e aquicultura: Brasil 2010. Brasília, 2012. Disponível em: http://www. uesc.br/cursos/pos_graduacao/mestrado/animal/biblio grafia2015/luis4.pdf. Acesso em: 29/05/2017.

BRITO, T.P.; OLIVEIRA, A.N.D.; SILVA, D.A.C.; ROCHA, J.A.S. Caracterização socioeconômica e tecnológica da atividade de pesca desenvolvida em São João de Pirabas - Pará - Brasil. Ambiência. v.11, n.3, p.699-720, 2015.

CAMPOS, A.G; CHAVES, J.V. Perfil laboral dos pescadores artesanais no Brasil: insumos para o programa seguro defeso. Boletim do Mercado de Trabalho. v.22, n.1, p.61-73, 2016.

CARVALHO JUNIOR, J.R.; CARVALHO, N.A.S.S.; NUNES, J.L.G.; CAMÕES, A.; BEZERRA, M.F.C.; SANTANA, A.R.; NAKAYAMA, L. Sobre a pesca de peixes ornamentais por comunidades do rio Xingu, Pará Brasil: relato de caso. Boletim do Instituto de Pesca. v.35, n.3, p.521-530, 2009.

CINTRA, I.H.A.; JURAS, A.A.; SILVA, K.C.A.; TENÓRIO, G.S.; OGAWA, M. Apetrechos de pesca utilizados no reservatório da Usina Hidrelétrica de Tucuruí (Pará, Brasil). Boletim Técnico-Científico do CEPNOR. v.9, n.1, p.67-79, 2009.

COE, C.M. Avaliação da atividade pesqueira na comunidade de pescadores artesanais de Bitupitá, município de Barroquinha, Ceará. Fortaleza, CE. 
Dissertação de Mestrado. Universidade Federal do Ceará - UFC; 2016.

COSTA, A.C.L.; SILVA JUNIOR, J.D.A.; CUNHA, A.C.; FEITOSA, J.R.P.; PORTELA, B.T.T.; SILVA, G.G.C.; COSTA, R.F. Índices de conforto térmico e suas variações sazonais em cidades de diferentes dimensões na região Amazônica. Revista Brasileira de Geografia Física. v.6, n.3, p.478-87, 2013.

FAO. The world state of fishery and aquaculture. Rome, Food and agriculture organization, 2012.

FONSECA, J.S.; MARTINS, G.A. Curso de Estatística. São Paulo, Atlas, 2008.

ISAAC, V.J.; ROCHA V.L.C.; MOTA, S. Considerações sobre a legislação da "piracema" e outras restrições da pesca da região do Médio Amazonas. In: L.G. FURTADO; A.F. MELLO; W. LEITÃO (eds.), Povos das águas: realidade e perspectiva na Amazônia. Belém, Museu Paraense Emilio Goeldi, p. 187-211, 1993.

INONATA, S.O.; FREITAS, C.E.C. A pesca comercial no médio rio Negro: aspectos econômicos e estrutura operacional. Boletim de Instituto de Pesca. v.41, n.1, p.79-87, 2015.

KÖPPEN, W.; GEIGER, R. Klimate der Erde. Gotha, Verlag Justus Perthes, 1928.

LOURENÇO, C.F.; FÉLIX, F.N.; HENKEL, J.S.; MANESCHY, M.C. A pesca artesanal no Estado do Pará. Belém, Seteps/Sine-PA, 2003.

McGRATH, D.G.; CARDOSO, A.; ALMEIDA, O.T.; PEZZUTI, J. Constructing a policy and institutional framework for an ecosystem-based approach to managing the Lower Amazon floodplain. Environment, Development and Sustainability, v.10, n.1, p.677-695, 2008.

NOGUEIRA, L.S.M; SOUZA, D.M.; SANTA BRÍGIDA, A.M.B. Segurança e saúde dos pescadores artesanais no estado do Pará. São Paulo, Fundacentro, 2017.

PETRERE JUNIOR, M. Setor pesqueiro: análise da situação atual e tendências do desenvolvimento da indústria da pesca. Manaus, Ibama/PróVarzea, 2004.

SÁ-OLIVEIRA， J.C.; VASCONCELOS， H.C.G.; PEREIRA, S.W.M.; ISAAC-NAHUM, V.J.; TELESJUNIOR, A.P. Caracterização da pesca no Reservatório e áreas adjacentes da UHE Coaracy
Nunes, Ferreira Gomes, Amapá - Brasil. Biota Amazonia. v.3, n.3, p.83-96, 2013.

SANTOS, M.A.S. A cadeia produtiva da pesca artesanal no Estado do Pará: estudo de caso no Nordeste Paraense. Amazônia: Ciência \& Desenvolvimento. v.1, n.1, p.61-81, 2005.

SANTOS-FILHO, A.P.; SILVA, L.M.A.; BITTENCOURT, S.C.S.; NAKAYAMA, L.; ZACARDI, D.M. Levantamento socioeconômico da atividade pesqueira artesanal na vila do Sucurijú, Amapá, Brasil. Boletim Técnico e Científico do CEPNOR. v.11, n.1, p.129-141, 2011.

SCHAFER, A.G.; REIS, E.G. Artisanal fishing areas and traditional ecological knowledge: the case study of the artisanal fisheries of the Patos Lagoon estuary (Brazil). Marine Policy. v. 32, n.1, p. 283-292, 2008.

SEIXAS, C.S.; BEGOSSI, A. Central Place optimal foragin theory: population and individual analyses of fishing strategies at Aventureiro (Ilha Grande, Brazil). Journal of the Brazilian Association for the Advancement of Science. v.52, n.2, p.85-92, 2000 .

TRIOLA, M.F. Introdução à Estatística. Rio de Janeiro, LTC Editora, 2005.

VAZ, E.M. Caracterização da atividade pesqueira praticada no lago Maicá, município de Santarém, Pará. Santarém, PA. Monografia. Universidade Federal do Oeste do Pará - UFOPA; 2016.

WALTER, T. Ecologia da pesca artesanal no lago Paranoá-Brasília-DF. São Carlos, SP. Dissertação de Mestrado. Universidade de São Paulo - USP; 2000.

ZACARDI, D.M. Aspectos sociais e técnicos da atividade pesqueira realizada no rio Tracajatuba, Amapá, Brasil. Acta of Fisheries and Aquatic Resource. v.3, n.2, p. 31-48, 2015.

ZACARDI, D.M.; PONTE, S.C.S.; SILVA, A.J.S. Caracterização da pesca e perfil dos pescadores artesanais de uma comunidade às margens do rio Tapajós, Pará. Amazônia: Ciência e Desenvolvimento. v.10, n.19, p.129-148, 2014.

ZACARDI, D.M.; SARAIVA, M.L.; VAZ, E.M. Caracterização da pesca artesanal praticada nos lagos Mapiri e Papucu às margens do rio Tapajós, Santarém, Pará. Revista Brasileira de Engenheira de Pesca v.10, n.1, p.32-44, 2017. 